Published in final edited form as:

Tetrahedron Lett. 2007 February 26; 48(9): 1637-1639.

\title{
A new palladium-mediated approach to 4- $\mathrm{N}$-arylamino-1-butanols from peroxidic tetrahydrofuran and primary aromatic amines
}

\author{
Henry F. Russella, ${ }^{*}$, John. B. Bremnerb, Jennifer Bushelle-Edghilla ${ }^{\mathrm{a}}$, Melissa R. Lewis ${ }^{\mathrm{c}}$, \\ Stacey R. Thomas ${ }^{\mathrm{a}}$, and Floyd Bates II \\ a Department of Science and Mathematics, Johnson C. Smith University, Charlotte, NC 28216, USA \\ b Department of Chemistry, University of Wollongong, Wollongong NSW 2522 Australia
}

\begin{abstract}
Reaction of primary aromatic amines with peroxidic tetrahydrofuran (THF) in the presence of hydrogen and $10 \%$ palladium on carbon catalyst results in THF ring opening to give $4-\mathrm{N}$-arylamino-1butanols in good yield. The reaction mechanism is believed to involve a free-radical sequence resulting in an imino alcohol subsequently reduced to product.
\end{abstract}

\section{Keywords}

Palladium catalyzed; Ring opening; 4-Amino-1-butanols; Hydrogenation; Tetrahydrofuran hydroperoxide

$\mathrm{N}$-Substituted 4-amino-1-butanols have been synthesized by various two and three step methods $1,2,3$ and, somewhat pertinent to this report, by high pressure hydrogenation with ring opening of dihydrooxazines using $\mathrm{Pd} / \mathrm{C} .{ }^{4}$ They are useful as solvents, plasticizers, and dye intermediates. Their preparation is also of biomedical interest since tests have shown that the $p$-aminobenzoate of 4-diethylamino-1-butanol is a more effective anesthetic than cocaine. ${ }^{2} \mathrm{An}$ ether derivative of 4-[(4'-methoxyphenyl)amino]butan-1-ol was recently shown ${ }^{5}$ to have antagonist activity at calcium T-type channels; the required aminobutanol precursor in this case was obtained via a two step sequence starting from reaction of succinic anhydride with the aromatic amine followed by hydride reduction of the intermediate amide acid.

Therefore, the unanticipated isolation of 4-\{1"-[(2'-aminophenyl)methyl]benzimidazole $\}-1$ butanol (2a) (Table 1) as well as the expected amine from the reduction of the corresponding nitro compound in THF with $\mathrm{Pd} / \mathrm{C}$ and hydrogen, led us to investigate the general applicability of this relatively simple and mild preparation of aminobutanols. To our knowledge this reaction has not been described previously. ${ }^{6} \mathrm{~A}$ brief series of reactions using various aromatic and aliphatic amines, in THF under a hydrogen atmosphere with $10 \% \mathrm{Pd} / \mathrm{C}$ was then investigated (Scheme 1) and the results are reported in this paper.

In a typical reaction, a solution of amine $1 \mathrm{e}(1.86 \mathrm{~g}, 20 \mathrm{mmole})$ and $10 \% \mathrm{Pd} / \mathrm{C}$ catalyst $(0.4 \mathrm{~g}$, $0.02 \mathrm{~g}$ per mmole of amine) in $100 \mathrm{~mL}$ of peroxidic THF (CAUTION: Handle peroxidic THF with care ${ }^{7}$ ) was stirred under a hydrogen atmosphere (1 atm) for 24-36 hr at room temperature.

*Corresponding Author. Tel.: +1 704378 1054; fax: +1 704378 1213; email: hrussell@ jcsu.edu.

cPresent address: $40370^{\text {th }}$ St., Seat Pleasant, MD 20743, USA

Publisher's Disclaimer: This is a PDF file of an unedited manuscript that has been accepted for publication. As a service to our customers we are providing this early version of the manuscript. The manuscript will undergo copyediting, typesetting, and review of the resulting proof before it is published in its final citable form. Please note that during the production process errors may be discovered which could affect the content, and all legal disclaimers that apply to the journal pertain. 
When TLC showed the absence of starting amine, the catalyst was filtered and the filtrate concentrated under vacuum to give crude product $\mathbf{2 e}$ as an oil. (NOTE: Before this evaporation, the filtrate should be checked for the presence of any residual peroxide (starch-iodide test ${ }^{7}$ ) and evaporation should only proceed if this is negative.) Crude $\mathbf{2 e}$ was purified as described in footnote 8. Other crude products were also oils except for $2 \mathrm{a}$ which was a crystalline solid. Crude compounds $\mathbf{2 b}-\mathbf{e}$ were vacuum distilled or chromatographed on silica except $\mathbf{2 a}$ which was isolated as a solid byproduct. Compounds $\mathbf{2} \mathbf{b}^{1}, \mathbf{2 c},{ }^{4}$ and $\mathbf{2} \mathbf{d}^{5}$ had been previously reported, but were accessed by different routes. New compounds $2 \mathbf{a}^{8}$ and $\mathbf{2} \mathrm{e}^{9}$ were characterized by elemental analyses and ${ }^{1} \mathrm{H}$ and ${ }^{13} \mathrm{C}$ NMR. The main repetitive NMR features of all compounds are those of the aminobutanol portion of the molecules: a 4-proton multiplet around $1.6 \delta$ was assigned to the C-2 and C-3 protons and two 2-proton broadened triplets around 3.0 and 3.6 $\delta$ were ascribed to the methylene protons adjacent to the nitrogen and the oxygen respectively. The ${ }^{13} \mathrm{C}$ NMR spectra show the chemical shifts of the signals for the four carbons of the aminobutanol portion of the molecule being relatively consistent thus making them useful for quick identification.

The initial results of this investigation are shown in Table 1 and indicate that only primary aromatic amines react. It was also found that THF solvent containing THF hydroperoxide was essential for the reaction to proceed. The solvent used was unstabilized THF which had been exposed to air. When THF from a newly opened bottle (or stabilized THF) was used the reactions did not proceed. Additional evidence for the involvement of THF hydroperoxide is the fact that a larger scale reaction using $p$-anisidine ceased after 1 day with only partial conversion to aminobutanol product but, upon evaporation of the solvent and replacement with air-exposed THF, the reaction continued to completion.

A possible free radical-based mechanism for this ring opening process is shown in Scheme 2. Cleavage of THF hydroperoxide results in the peroxide free radical A. Radical A can then abstract hydrogen from the 2 position of THF to form radical $\mathbf{B}$. Either radical $\mathbf{A}$ or $\mathbf{B}$ could then abstract hydrogen from the amine nitrogen to form the resonance stabilized aminyl radical $\mathbf{C}$ which could in turn couple with radical $\mathbf{B}$ to form the 2-amino-THF intermediate $\mathbf{D}$. At this point the ring of the palladium-complex opens to form imine $\mathbf{E}$ which then could be hydrogenated 10 to the final product 2.

Several facts support this proposed mechanism. Firstly, the THF solvent initially being used was unstabilized and had been open for many months thus allowing a buildup of THF hydroperoxide. This strongly implies that the presence of THF hydroperoxide is necessary for reaction to occur. Secondly, the fact that only aromatic amines react strengthens the free radical approach since they can stabilize the amino free radical $\mathbf{D}$ by resonance. Formation of imine intermediate $\mathbf{E}$ with subsequent reduction is supported by two observations. One, the presence of hydrogen is necessary for reaction to occur. The reaction did not proceed in a nitrogen atmosphere and a reaction of $\mathbf{1} \mathbf{c}$ in air gave multiple products. Two, the requirement for formation of the imine explains the non-reactivity of secondary aromatic amines since imine formation is not possible

In summary, a new mild procedure for the one pot conversion of aromatic primary amines to 4- $\mathrm{N}$-arylamino-1-butanols in the presence of peroxidic THF and $\mathrm{Pd} / \mathrm{C}$ and hydrogen has been demonstrated. This reaction should provide access to a range of new amino alcohols of value in further synthesis.

\section{Acknowledgements}

The authors acknowledge support of The National Institutes of Health, NIGMS, MBRS-SCORE grant GM 065299 and MBRS-RISE grant GM 58042, and NSF Instrumentation grant 0116393. The assistance of Drs. Craig Ogle and Cliff Carlin of the University of North Carolina, Charlotte, is also appreciated. 


\section{References and notes}

1. Wichterle O. Collect Czech Chem Commun 1949;14:209-18.

2. Lunsford CD, Murphy RS, Rose EK. J Org Chem 1957;22:1225-1228.

3. Flanikin JM, Collins JC, Lanz M, Singaram B. Organic Letters 1999;1:799-801. [PubMed: 16118886]

4. Winberg, HE. US Patent. 2,628,978. 1953.

5. McCalmont WF, Patterson JR, Lindenmuth MA, Heady TN, Haverstick DM, Gray LS, Macdonald TL. Bioorg Med Chem 2005;13:3821-39. [PubMed: 15863008]

6. While ring opening of THF on attack by amines has been reported previously this involves complexing of the THF with cationic metal compounds. See: Boisson C, Berthet JC, Lance M, Nierlich M, Ephritikhine M. Chem Commun 1996:2129.Borkowski SL, Jordan RF, Hinch GD. Organometallics 1991;10:1268.

7. Furniss, BS.; Hannaford, AJ.; Smith, PWG.; Tatchell, AR. Vogel's Textbook of Practical Organic Chemistry. 5. Longman, Harlow; England: 1989. p. 406-552.

8. 4-\{1"-[(2'-aminophenyl)methyl]benzimidazole $\}$ butan-1-ol (2a)This compound was recrystallized from methanol to give pale orange crystals; $\mathrm{mp}\left(135.5-137^{\circ} \mathrm{C}\right) .{ }^{1} \mathrm{H}-\mathrm{NMR}\left(\mathrm{DMSO}-\mathrm{d}_{6}\right) \delta: 1.4-1.8$ (m, $\left.4 \mathrm{H}, \mathrm{CH}_{2}-2 \& \mathrm{CH}_{3}-3\right), 3.0-3.25\left(\mathrm{~m}, 2 \mathrm{H}, \mathrm{CH}_{2}-4\right), 3.35-3.65\left(\mathrm{~m}, 2 \mathrm{H}, \mathrm{CH}_{2}-1\right), 4.5$ (t, J = 5.0 Hz, $1 \mathrm{H}, \mathrm{NH}), 5.3(\mathrm{t}, 5.4 \mathrm{~Hz}, 1 \mathrm{H}, \mathrm{OH}), 5.4\left(\mathrm{~s}, 2 \mathrm{H}\right.$, benzylic $\left.\mathrm{CH}_{2}\right), 6.4-6.85(\mathrm{~m}, 3 \mathrm{H}, \mathrm{ArH}), 7.0-7.35$ (multiplet with prominent doublet, $\mathrm{J}=9.3 \mathrm{~Hz}, 3 \mathrm{H}, \mathrm{ArH}), 7.45-7.55(\mathrm{~m}, 1 \mathrm{H}, \mathrm{ArH}), 7.6-7.75(\mathrm{~m}, 1 \mathrm{H}$,

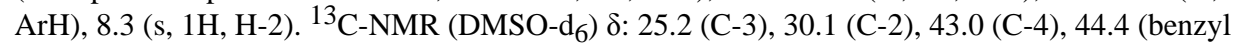
$\left.\mathrm{CH}_{2}\right), 60.5$ (C-1); 110.35, 110.75, 115.7, 119.4, 120.2, 121.5, 122.3, 128.1, 128.9, 134.0, 143.5, 144.3, 146.0 (All Ar-C). Anal: Calcd. for $\mathrm{C}_{18} \mathrm{H}_{21} \mathrm{~N}_{3} \mathrm{O}$ : C 73.19; H 7.17; N 14.23\%. Found: C 72.98; H 7.23; N $14.10 \%$.

9. 4-[(4-Fluorophenyl)amino]butan-1-ol (2e)This compound was isolated from the crude reaction product ( $\sim 90 \%$ yield) by flash chromatography on silica gel using ethyl acetate/hexane (3/2) as eluent; $2 \mathbf{e}$ was isolated as an oil ( $80 \%$ yield); bp $148-150{ }^{\circ} \mathrm{C} / 3$ Torr. ${ }^{1} \mathrm{H}-\mathrm{NMR}\left(\mathrm{CDCl}_{3}\right) \delta: 1.65\left(\mathrm{~m}, 4 \mathrm{H}, \mathrm{CH}_{2}-2\right.$ \& 3)), 3.1 (m with prominent broad singlet, $4 \mathrm{H}, \mathrm{CH}_{2}-4, \mathrm{~N}-\mathrm{H}$ and $\left.\mathrm{O}-\mathrm{H}\right), 3.65\left(\mathrm{t}, \mathrm{J}=6 \mathrm{~Hz}, 2 \mathrm{H}, \mathrm{CH}_{2}-1\right), 6.55$ $\left(\mathrm{m}, 2 \mathrm{H}, \mathrm{ArH}-2^{\prime}\right), 6.9$ (m, 2H, ArH-3'), ${ }^{13} \mathrm{C}-\mathrm{NMR}\left(\mathrm{CDCl}_{3}\right) \delta: 26.0(\mathrm{C}-3), 31.5(\mathrm{C}-2), 44.8(\mathrm{C}-4), 62.15$ (C-1), 114.2 (ArC), 115 (ArC'), 145.1 (ArC-1'), 161.5 (ArC-4'). Anal: Calcd. for $\mathrm{C}_{10} \mathrm{H}_{14} \mathrm{FNO}$ : C, 65.55; H, 7.70; F, 10.37; N, 7.65\%. Found: C, 65.34; H, 7.84; F, 10.48; N, 7.60\%.

10. Tang W, Zhang X. Chem Rev 2003;103:3029. [PubMed: 12914491]Saaby S, Knudsen KR, Ladlow M, Ley SV. Chem Commun 2005:2909. 


$$
\underset{\text { 1a-e }}{\mathrm{ArNH}_{2}}+\square_{\mathrm{O}} \frac{\mathrm{H}_{2} ; \mathrm{Pd} / \mathrm{C} ; 1 \mathrm{~atm} .}{\text { peroxidic THF }} \underset{\mathrm{H}}{\longrightarrow \text { 2a-e }}
$$

Scheme 1.

THF ring opening to form 4- $N$-arylamino-1-butanols. 

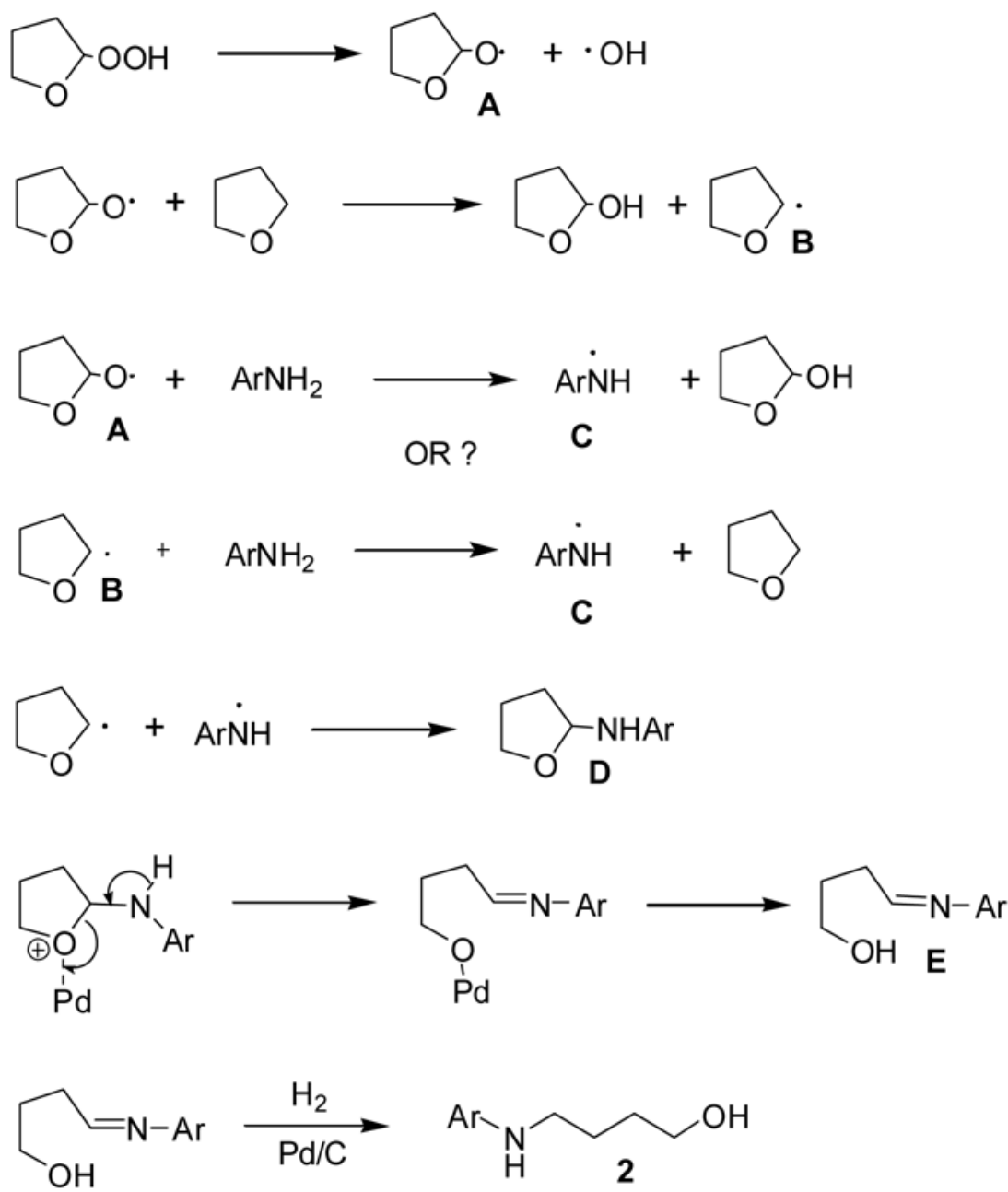

Scheme 2.

A plausible mechanism for Pd mediated THF ring opening. 
Russell et al.

Page 6

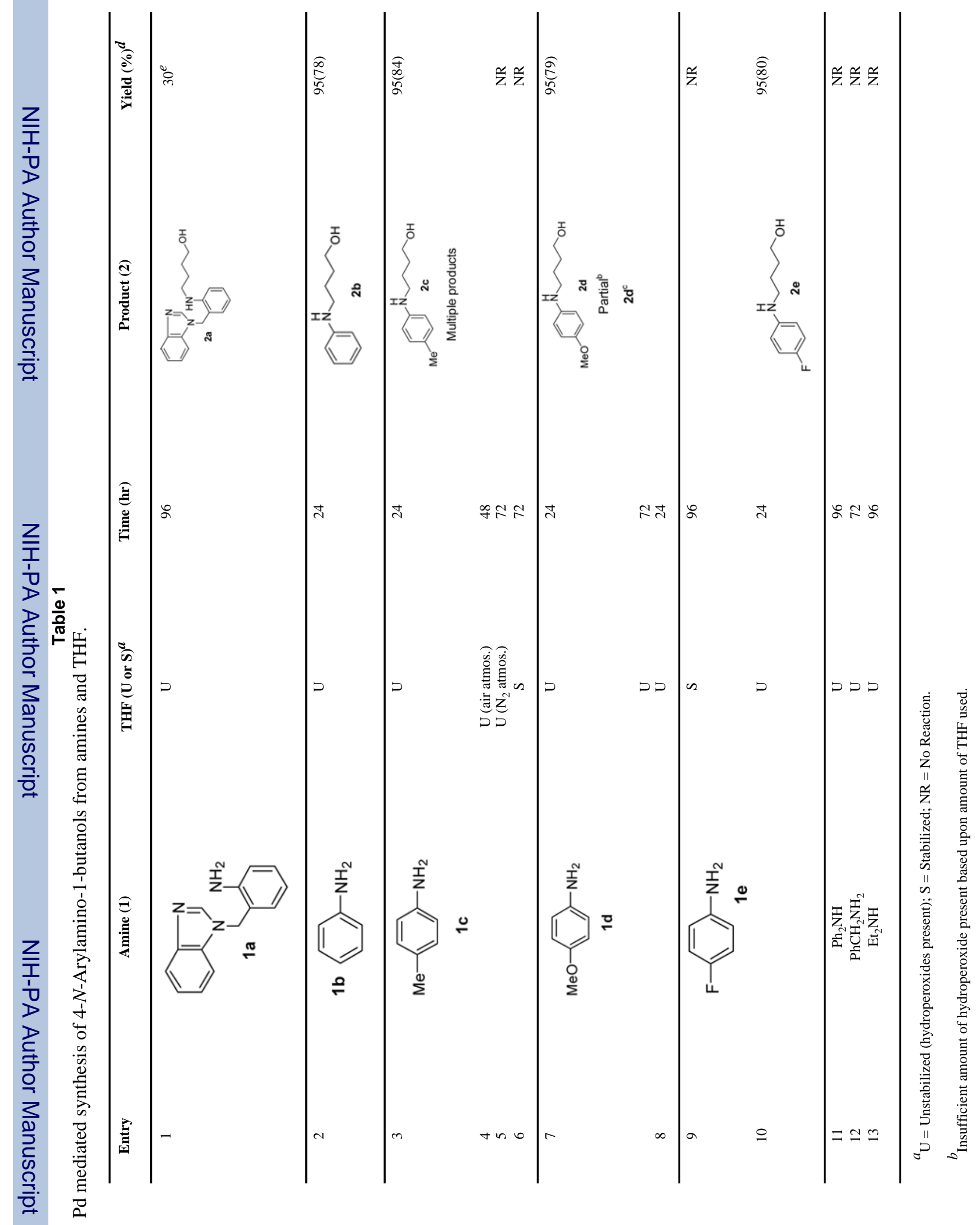

Tetrahedron Lett. Author manuscript; available in PMC 2007 December 10. 


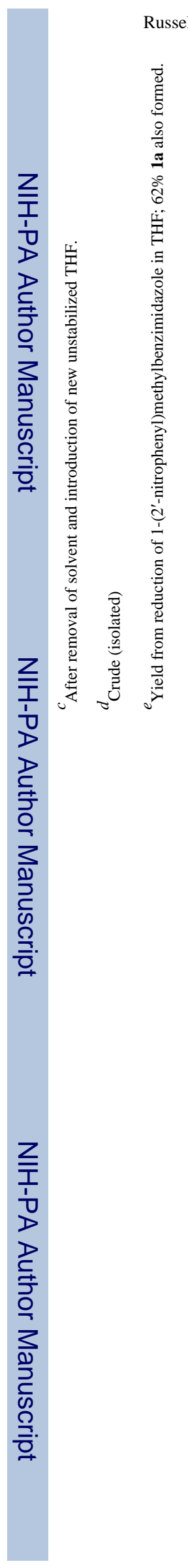

Page 7

Tetrahedron Lett. Author manuscript; available in PMC 2007 December 10. 